\title{
A NOÇÃo de PATHOS DIVINO EM ABRAHAM J. HESCHEL
}

\author{
THE NOTION OF DIVINE PATHOS IN ABRAHAM J. HESCHEL
}

Edson FeRnANDo de ALmeidA ${ }^{(*)}$

\begin{abstract}
RESUMO
Este artigo tem como objetivo apresentar a noção de pathos divino no pensamento de Abraham J. Heschel. Foi a partir de uma abordagem fenomenológica da religião que Heschel encontrou um espaço de dignidade para o profetismo bíblico. Operando a partir dos pressupostos da crítica husserliana, Heschel descobriu no profeta bíblico alguém que compreende a si mesmo na situação de Deus, na preocupação divina, não nas ideias e conceitos que tenha a respeito de Deus. A tal situação Heschel chamou de pathos divino e a resposta a tal situação Heschel chamou de simpatia. A noção de pathos divino é o mais importante legado deixado pela filosofia da religião ou teologia profunda de Abraham Heschel.
\end{abstract}

Palavras-Chave: Heschel. Pathos divino. Profetismo bíblico. Simpatia.

\section{ABSTRACT}

This article aims to present the notion of divine pathos in the thought of Abraham J. Heschel. It was from a phenomenological approach to religion that Heschel found a dignified space for biblical prophecy. Operating from the assumptions derived from Husserl's criticism, Heschel found in the biblical prophet someone who understands himself in God's situation, in the divine concern, not from ideas and concepts about God. This situation Heschel called the divine pathos and the answer to this situation Heschel called sympathy. The notion of divine pathos is the most important legacy of the philosophy of religion or profound theology of Abraham Joshua Heschel.

KEYWORDS: Heschel. Divine pathos. Biblical prophecy. Sympathy.

\section{INTRODUÇÃO}

Desde os primórdios do pensamento cristão o universo religioso da profecia hebraica tem sido substancialmente explorado por setores significativos da teologia cristã. Na reflexão teológica moderna, entre as quais podemos mencionar a teologia política europeia e a teologia da libertação latino-americana, a consciência profética sempre apareceu como elemento central e determinante. Especialmente na teologia bíblica latino-americana, a exegese do corpus profético encontrou um espaço significativo, tornando-se o núcleo de uma reflexão que encontrou na crítica da profecia hebraica os fundamentos decisivos do seu discurso teológico (SCHWANTES, 1987).

Essencialmente marcada por uma abordagem de cunho exegético e histórico, tal leitura do profetismo bíblico não possui como objetivo uma

\footnotetext{
${ }^{(*)}$ Doutor em Teologia pela PUC-Rio. Pós-doutorando em Ciência da Religião pela UFJF. Professor Titular do Seminário Teológico Batista do Sul do Brasil, Brasil. E-mail: edson.fernando@uol.com.br; edsonfernandodealmeida@gmail.com.
} 
abordagem e compreensão teológico-filosófica da consciência profética, como encontramos sistematizado no pensamento de Abraham Joshua Heschel. Apoiado numa aproximação fenomenológica da consciência profética, Heschel descobriu no profetismo literário bíblico a noção de pathos divino que se tornou a plataforma de um pensamento teológico que ousou questionar o axioma da impassibilidade divina.

\section{ABRAHAM HESCHEL: A INTERFACE FENOMENOLÓGICA ENTRE A TRADIÇÃO JUDAICA E O MUNDO FILOSÓFICO OCIDENTAL}

Foi a partir de uma abordagem fenomenológica que Abraham Joshua Heschel encontrou um espaço de dignidade para a religião do profetismo bíblico (KAPLAN; DrESNER, 1998). Tal abordagem tomou como seu objeto especifico a experiência religiosa. Estruturando-se a partir dos pressupostos da crítica husserliana, que com sua redução explodira a estreiteza do conceito de experiência reduzido às ciências, a fenomenologia da religião abriu espaço para a experiência viva do homem no seu mundo de todos os dias (BINGEMER; REY PUENTE, 2011).

Segundo Alexandre Leone, a linguagem fenomenológica funcionou para Heschel como uma interface entre a tradição bíblica judaica e o mundo intelectual ocidental, tornando visível à cena moderna um espaço de reflexão onde a experiência profética pudesse ser pensada para além das reduções cientificistas de uma psicologia ou sociologia da religião (LEONE, 2002). Num dos capítulos finais do livro The Prophets (HESCHEL, 2011), transparece o recurso à fenomenologia contra o reducionismo de ordem psicológica. Para Heschel,

O erro na abordagem psicológica tem ocorrido no seu pré-julgamento; ela tem negado a priori aquilo que supostamente exploraria. Portanto, ao invés de elucidar a experiência profética, ela tem tentado dissolvê-la através de sua explicação. Consistente com sua visão da vida interior como uma continuidade ou como um processo, ela tem tentado olhar para a inspiração profética como uma continuidade de um processo que começou na imaginação ou no subconsciente. Ela tenta explicá-lo como o produto das experiências pessoais do profeta, cenas, paixões, tensões, frustrações, para relacioná-las ao que se chama de complexos. Profecia, então, seria apenas uma maneira de fazer conexões entre os diferentes elementos da experiência do profeta, uma organização única dos impulsos que suas sensações despertaram (HESCHEL, 2011, p. 520-521).

A crítica de Heschel procura desvencilhar-se das reduções cientificistas do fenômeno religioso que caracterizaram as abordagens modernas, procurando, na trilha de pensadores como Rudolf Otto e Gerardus van der Leeuw, superar os 
determinismos que desqualificaram a essência de tal fenômeno, aproximandose, não daquilo que seriam os epifenômenos desta experiência, mas da experiência mesma que se concretiza como o sentido do sagrado.

Dois trechos do livro $O$ homem a procura de Deus e um terceiro, do livro Deus em busca do homem, parecem confirmar tal hipótese. No primeiro, Heschel descreve a sua chegada à Universidade de Berlim para os seus estudos de Filosofia:

Eu pensava que meus professores estavam escravizados à moda de pensar gregogermânica. [...] Para eles a religião era um sentimento. Para mim a religião incluía as intuições da Torá, que é uma visão do homem do ponto de vista de Deus. [...] Para eles Deus era uma ideia, um postulado da razão. Eles lhe concediam o estado de ser uma possibilidade lógica. Mas supor que ele tinha existência seria um crime contra a epistemologia. O problema para meus professores era como ser bom. Nos meus ouvidos a questão soava: como ser santo [...] O bem não pode existir sem o santo. O bom é a base, o santo é o cume. Um homem não pode ser bom se não procura ser santo (HESCHEL, 1974, pp. 124-125).

No segundo trecho do mesmo livro Heschel quebra o invólucro da significação racional como única forma de conferir dignidade à observação das mitzvoth:

A religião não está dentro, mas além dos limites da pura razão. Sua tarefa não é competir com a razão, ser uma fonte de ideias especulativas, mas ajudar-nos quando a razão só nos ajuda parcialmente. Sua significação deve ser entendida em termos compatíveis com o senso do inefável. Frequentemente, quando os conceitos falham, onde o conhecimento racional termina, começa o significado da observância. Sua finalidade não é essencialmente servir à higiene, à felicidade ou à vitalidade do homem. Sua finalidade é dar santidade à higiene, grandeza à felicidade, espírito à vitalidade (HESCHEL, 1974, p. 136).

Por último, a proposta de Heschel de uma teologia profunda para além de uma filosofia exercida como processo de pensamento-conceito, reduzida à análise do conteudismo do pensamento, pela via de suas suposições e doutrinas:

Para aprender a profundidade da fé religiosa, nós tentaremos determinar não tanto o que a pessoa está apta a expressar, como o que ela não está apta a expressar, os 'insights' que nenhuma linguagem pode traduzir. Devemos lembrar sempre que o perigo mais importante para a filosofia, afora o ócio e a imprecisão, é o escolasticismo, a essência do qual é objetivar o que é vago como se fosse preciso tentar adaptá-lo a uma categoria lógica exata. De fato, um dos erros fatais da teologia conceitual tem sido a separação da existência dos atos religiosos das afirmações acerca de si mesma. Idéias a respeito da fé não devem ser estudadas totalmente separadas dos momentos da fé. Se uma planta é arrancada do solo onde está, removida de seus ventos, dos raios de sol e vida-ambiente, e conservada numa estufa - observações feitas com tal planta revelarão sua natureza primordial? A intimidade crescente do homem que penetra e se curva 
para a luz de Deus dificilmente pode ser transplantada de uma simples reflexão. Removido de seu ambiente na vida humana, murcha como uma rosa prensada entre as páginas de um livro. Religião é, naturalmente, pouco mais do que um remanescente dissecado de uma antiga realidade de vida quando é reduzida a termos e definições, a códigos e catecismos. Pode somente ser estudado em seu habitat natural de fé e piedade, numa alma onde o divino está dentro de todos os conceitos (HESCHEL, 1975, pp. 21-22).

\section{A TEOLOGIA DO PATHOS EM ABRAHAM HESCHEL ${ }^{1}$}

O objetivo principal de Abraham Heschel ao escrever uma de suas mais importantes obras, De Prophetie - Das prophetische Bewusstsein, foi analisar e interpretar a consciência profética a partir do profetismo literário bíblico, com foco entre o VIII e VI séculos. Originalmente o texto foi escrito como requisito para a obtenção do seu doutorado em filosofia na Universidade de Berlim, nos anos 30 do século passado. Nos anos 1960, reescreveu-o no contexto estadunidense.

Segundo Heschel (BERKOVITS, 1964), dois aspectos podem ser distinguidos na experiência profética: um objetivo e outro subjetivo. O aspecto objetivo diz respeito à realidade de Deus em seu caráter transcendente, como se apresenta à consciência profética. O aspecto subjetivo tem a ver com a resposta do profeta à força dessa presença. No dizer de Alexandre Leone, "o profeta hescheliano é aquele que se descobre objeto da visita divina” (LEONE, 2002, p. 104). A investigação do elemento objetivo de tal visita, Heschel chamou teologia profética. Ao elemento subjetivo de tal experiência, denominou religião profética.

O que o profeta conhece da realidade de Deus não advém de silogismos lógicos e induções. O que o profeta sabe de Deus vem do seu confronto com a divina presença. Ele o conhece a partir da afetação que sofre pela via do pathos divino. Seu conhecimento, por isso mesmo, é mais intuitivo, uma espécie de relacionamento que encontra na metáfora dos amantes uma expressão mais apropriada. O Deus encontrado pelo profeta é um Deus interessado no homem. Dada a vivacidade deste encontro, o que o profeta comunica não são ideias sobre Deus, mas testemunhos de um Vivente que se dirige ao homem na dinâmica de um cuidado. Por tal motivo, a linguagem metafísica está fora da cena profética.

\footnotetext{
' Para uma apresentacao resumida da teologia patética de Heschel utilizaremos o artigo de Eliezer Berkovits, Dr. A. J. Heschel'sTheologyofpathos(BERKOVITZ, 1964). Não obstante a certeira e clara apresentação do conceito teológico de pathos em Heschel, na parte inicial do artigo, o objetivo central de Berkovits foi fazer um forte questionamento aos aspectos centrais da construção teológica hescheliana.
} 
Segundo Leone (2002, p. 102), "se há alguma metafísica no pensamento do profeta, ela se volta principalmente para o sentido das ações humanas e para a importância do viver dos homens." O conteúdo do testemunho profético não é a essência do ser divino, é seu pathos, cuja intencionalidade desborda em preocupação, cuidado e zelo pelo mundo humano. Por isso a alma do profeta, afirma Leone, queima em compaixão pelos seres humanos.

\section{Continua Leone:}

O estilo do discurso profético revela não a essência metafísica de Deus, mas antes e sobretudo o interesse 'emocional' divino para com a situação humana. A forma do discurso profético é emocional, seu tema é a vida de todo o povo. Essa vida das pessoas é ela mesma coalhada de contradições. E essas contradições vão também se refletir na preocupação divina, que por um lado afirma a importância do homem para Deus; e por outro lado condena e repreende a injustiça, a idolatria e mesquinhez da sociedade humana (LEONE, 2002, p. 102-103).

O questionamento da noção de theos apathes não é desconhecido da teologia bíblica e da filosofia da religião. A originalidade do pensamento hescheliano está em expandir tal conceito elevando-o ao extremo, chamando-a de pathos divino. Deus não apenas se preocupa com a humanidade, Deus também é afetado por ela. Ou seja, o Deus bíblico é um Deus pático, afetado pelos eventos do mundo e reagente a tais afecções. Deus revela-se à humanidade não em sua essência, ou na sua abstrata abscondidade, mas em uma pessoal e íntima relação com ela. Ele não simplesmente ordena e espera obediência dos seres humanos. Ele é movido e afetado pelos eventos históricos. Tais eventos e ações humanas provocam no Deus vivo zelo e alegria, regozijo e raiva. Segundo Heschel (1975), quando Deus criou o mundo, viu que o mundo era bom. Mas, quando Deus vê a historia humana, Ele não pode dizer a mesma coisa.

É a força do pathos que a linguagem profundamente antropomórfica do profetismo bíblico quer expressar. As ações humanas são capazes de mover Deus, de afetá-lo, de causar-lhe dor ou prazer. O elemento de fundo aqui não é outro senão a noção de que o ser humano é importante para Deus. Se se desconecta tal linguagem antropomórfica da noção de pathos divino, o pensamento hescheliano faria confirmar a velha ideia de reduzir Deus a um ídolo à imagem e semelhança do humano.

Trata-se de um mistério que não pode ser alcançado racionalmente, que o Criador dos céus e da terra possa se comover e preocupar-se com a humanidade, deixando-se afetar por seus feitos e desfeitos. Tal caráter sui generis da teologia bíblica torna inócuo, por exemplo, o conceito de Deus como o Totalmente 
Outro, ou como Noumen. A alteridade e o tremendum são corolários do divino cuidado, não o contrário, como mostrou com clareza o teólogo Paolo Gambelini(2009), ao descrever o logos da teologia hescheliana na forma do pathos.

Por isso a linguagem conotativa será sempre a mais apropriada para referir-se ao pathos, pois "O caráter polissêmico e polivalente da poesia permite preservar a palavra na sua dimensão de evento" (GAMBERINI, 2009, p. 40). Daí a poética cortante do profetismo literário bíblico.

O abismo que separa Deus e o mundo é transcendido, segundo a consciência profética, pelo pathos de Deus. A sua impenetrabilidade está atravessada por sua relacionalidade com o mundo dos afazeres humanos. Pathosé togetherness in holyotherness. (BERKOVITZ, 1964, p. 69). Eis, portanto, a base da teologia profética, o lado da experiência profética que diz respeito à objetividade da presença de Deus na vida do profeta.

O lado subjetivo desta experiência é a resposta do profeta a tal presença. A esta resposta Heschel chamou-a simpatia. O profeta responde ao pathos divino testemunhando-o, transmitindo-o, anunciando-o. Ele sente os sentimentos de Deus, Ele reage ao pathos com uma simpatia por Deus. Em absoluto contraste com o homem estoico, o profeta, ao ser tocado pelo pathos divino, torna-se uma homo simpatheticus. Ele se abre ao cuidado e preocupação divinos, comungando-os, em experiência e sofrimento por Deus e pelo mundo.

A dor de Deus é a sua dor. Sua comunhão com Deus é compaixão por Deus e sintonia com a transitividade do amor divino pela humanidade. A simpatia o torna guiado não por seus próprios sentimentos, mas pelos sentimentos de Deus. Na resposta simpática ao pathos, se "estabelece com o outro uma relação pessoal, pois este é encarado como realidade transcendente acessível por meio da afetividade." (LEONE, 2002, p. 118).

A simpatia é a resposta do profeta à inspiração, o correlativo à revelação. À sensibilidade transcendente, a resposta é a simpatia profética. Não se trata de uma assimilação ao ser divino, como no amor, mas assimilação da transitividade da preocupação divina pelo destino da humanidade. "O Profeta ouve a voz de Deus e sente o Seu coração. Ele tenta transmitir o pathos da mensagem com o seu logos" (HESCHEL, 2011, p. 33). Como um mensageiro sua alma transborda, falando como se o fizesse a partir da plenitude da sua simpatia. 
Para Berkovitz, é possível expressar a teoria de Heschel em uma única sentença:

De acordo com sua teologia do pathos, a ação humana evoca o pathos divino; de acordo com sua religião da simpatia, a compaixão divina evoca a simpatia profética. O homem afeta Deus e Deus afeta o profeta. No diálogo entre Deus e o homem, Deus responde com pathos, no diálogo entre o profeta e Deus, o profeta responde com simpatia. (BERKOVITZ, 1964, p. 70)

\section{UMA FENOMENOLOGIA DO PATHOS}

A noção de pathos divino se impõe desde a primeira linha do livro The Prophets. Estranheza e fascínio emanam da figura do profeta bíblico na hermenêutica hescheliana: "Este livro é sobre algumas das pessoas mais perturbadas que já existiram: homens cuja inspiração trouxe a Bíblia para dentro do ser - homens cuja imagem é nosso refúgio na aflição, e cuja voz e visão sustentam nossa fé." (HEschel, 2011, p. xxi). Para Heschel, a significância dos profetas não está no que disseram, mas no que foram e, a menos que acordemos para o que com eles aconteceu, não entenderemos o que quiseram dizer. Mas, pergunta Heschel: como fazê-lo, já que os momentos que viveram não são objetiváveis nem avaliáveis e, por isso mesmo não podem tornar-se objeto da analise cientifica? O que temos, segundo Heschel, é a consciência dos momentos que viveram preservada em palavras.

Portanto, como alcançar uma espécie de compreensão do profeta através da descrição de sua consciência para relacionar o seu vivido como refletido e expresso no registro escrito de tal experiência? Eis a tarefa a que se propõe Heschel, tendo como instrumento a redução fenomenológica.

O primeiro passo é a busca da superação da visão unilateral em sua dupla face: aquela que isolando a noção de inspiração acaba perdendo a visão da situação humana. $\mathrm{Ou}$, em contraste, aquela que reduz a visão da profecia inteiramente à vida dos profetas. No primeiro caso, ressalta-se o elemento transcendente com o perigo de uma mecanização da noção de revelação. A isso Heschel chamou de panteologia. No segundo, reduz-se a profecia a um fenômeno pessoal subjetivo desconsiderando-se "a consciência do profeta de sua confrontação com os fatos não decorrentes de sua própria mente" (HESCHEL, 2011, p. xii). A esse segundo elemento Heschel chamou de panpsicologia.

A rejeição de ambos os extremos deve brotar da percepção de que as palavras dos profetas dão testemunho de uma situação que desafia a panteologia e a panpsicologia. Análise cuidadosa mostra que a situação é composta de revelação e 
resposta, receptividade e espontaneidade, de evento e experiência. Eu sustento, entretanto, que as marcas do elemento pessoal devem ser rastreadas, não fora do ato profético, mas dentro dele (HESCHEL, 2011, p. xii).

Ao propor-se a tarefa da aproximação à consciência do profeta, para colocar a pergunta sobre sua singularidade, Heschel, adverte: explicar o profeta a partir de um conjunto de elementos preconcebidos é colocar "a carroça à frente dos bois". Quando explicar é o propósito, o entendimento (understanding) acaba sendo prejudicado. Isso acontece, por exemplo, quando o profeta, de antemão, é concebido como um poeta, um ativista, um moralista, um crítico. Se se o define assim, de forma preconcebida, corre-se o risco de perder a natureza essencial da profecia, embora o profeta seja tudo isso mesmo.

Por exemplo,

O viés que os scholars utilizam e que pode ser definido como um princípio, a saber, que nada pode ser reconhecido como um dado a menos que possa ser qualificado a priori como sendo capaz de explicação - além de ser pretensioso e questionável, obstrui a visão de grande parte da realidade e afeta seriamente nosso alcance para obter uma visão 'pristine' (pura, primitiva) para o que enfrentamos (HESCHEL, 2011, p. xiv).

E aqui se manifesta a fineza do olhar fenomenológico de Heschel:

Limitando a atenção para o que é dado nas fontes literárias, ou seja, os livros proféticos, tenho procurado ganhar alguns insights sobre a mente dos profetas e entender os momentos decisivos de sua existência a partir dessa perspectiva. Não foi minha intenção julgar a verdade do seu pedido de ter recebido revelação, nem resolver o descobrir as condições do enigma da profecia pela via das explicações psicológicas e sociológicas, nem ainda de sua possibilidade ou sugerir meios de sua verificação (HESCHEL, 2011, p. xiv).

Portanto, para chegar à consciência profética a redução hescheliana propõe o seguinte itinerário: "iluminar a demanda dos profetas; não explicar a sua consciência, mas entendê-la. Ao revelar as características decisivas da sua consciência, a estrutura essencial da experiência como refletida naquela consciência pode tornar-se manifesta” (HESCHEL, 2011, p. xiv).

\section{E arremata Heschel:}

O que eu busco é uma compreensão do que significa pensar, sentir, responder e agir como um profeta. Não faz parte da minha tarefa ir além de sua consciência, a fim de explorar o subconsciente ou chegar aos condicionamentos antecedentes e experiências dentro da vida interior do indivíduo. A suposição de que está além e abaixo do limiar da consciência do profeta nunca pode ser um substituto para a compreensão do que é exibido na própria consciência. Também não é possível confirmar o que ele afirma. Nós podemos chegar a algum conhecimento do que 
agitou o profeta como um profeta - das ideias pelas quais ele foi movido em determinados momentos; nós não podemos provar as realidades e eventos que precederam esses momentos (HESCHEL, 2011, p. xiv).

\section{Portanto,}

[...] Observação, inspeção, abordagem e sondagem, a pura visão do que nós encaramos, servem para nos apresentar à realidade do fenômeno e aguçar a nossa capacidade de formular perguntas que conduzem à descoberta do que é único sobre ele. De fato, isso requer mais esforço para entender quais questões não podem ser feitas e aquelas demandas que não podem ser atendidas. O que prejudica nosso olhar são os hábitos da visão tanto quanto os concomitantes mentais do ver. Nossa visão é impregnada com conhecimento ao invés de sentir dolorosamente a falta de saber o que vemos. O princípio para guardar na mente é conhecer o que nós vemos mais do que ver o que nós conhecemos (HESCHEL, 2011, p. xxiv).

\section{Ainda Heschel:}

Ao invés de culparmos as coisas por serem obscuras, deveríamos culpar a nós mesmos por sermos tendenciosos e prisioneiros de repetitividade auto-induzida. É preciso esquecer muitos clichês a fim de contemplar uma única imagem. Insight é o começo de percepções por vir, mais do que a extensão de percepções que já foram (HESCHEL, 2011, p. xxiv-xxv).

Portanto, estão dadas as coordenadas da redução fenomenológica hescheliana. Para operar tal redução o insight é ferramenta fundamental. Para Heschel a visão convencional opera com padrões e coerências, o que seria uma maneira de ver o presente no passado. O insight, ao contrário, é uma tentativa de pensar no presente, o que exige um deslocamento intelectual. Por isso, há que cultivar uma abertura para o não familiar, o inacreditável, o sem paralelo, o surpreendente, bem como suspender as crenças pessoais.

Para Heschel, "a situação de uma pessoa imersa nas palavras dos profetas é a de estar sendo exposta a uma ruptura incessante da indiferença”. E conclui: "é preciso um crânio de pedra para permanecer insensível a esses golpes" (Heschel, 2011, p. 25). Para o teólogo judeu é preciso suspender o julgamento e pensar livremente se se quer compreender um fenômeno. A suspensão do juízo é também a suspenção da indiferença. É estar envolvido. Para Heschel, cada reflexão faz aparecer o abismo que há entre os fenômenos e nós mesmos. "Se os reduzimos a objetos mortos da mente, nós os privamos do poder de nos afetarem, de nos falarem, de transcender nossas atitudes e compreensões." (HESCHEL, 2011, p. xxvi). 
$\mathrm{Na}$ escuta dos profetas não podemos permanecer sobre a pedra de nossa prudência e imparcialidade. Eles não nos oferecem reflexões sobre ideias em geral. Segundo Heschel, suas palavras atropelam nossas falsas ilusões de segurança, questionando-nos no alto de nossa prudência e imparcialidade. "Pode igualmente temer o submeter-se a suas estranhas certezas e resistir às suas tremendas reivindicações por causa da incredulidade ou impotência do espírito. Reflexão sobre os profetas dá lugar à comunhão com os profetas” (HESCHEL, 2011, p. Xxvi).

Reflexão pura pode ser suficiente para esclarecer o que a consciência dos profetas afirma, mas não para o que sua existência envolve. Para tal entendimento não é suficiente ter os profetas em mente; nós devemos pensar como se eles estivessem dentro das nossas mentes. Para eles estarem vivos e presentes para nós, precisamos pensar não sobre, mas nos profetas, com sua preocupação e seu coração. Sua existência envolve-nos. A menos que suas preocupações nos quebrem, nos doam, nos exaltem, nos realmente não o sentimos (HESCHEL, 2011, p. xxvi).

A profecia não é a simples aplicação de regras atemporais para situações humanas particulares. Para Heschel, a profecia bíblica é uma hermenêutica do entendimento divino do agora, do momento histórico particular da situação humana. Neste sentido, a profecia poderia ser descrita como a exegese da existência a partir da perspectiva divina. O entendimento profético é um entendimento (understanding) do entendimento (understanding), mais do que um entendimento (understanding) do conhecimento (knowledge). Para Heschel, a profecia divina é a exegese da exegese. Tal concepção envolve compartilhar a perspectiva da qual o entendimento original acontece. Interpretar a profecia bíblica de qualquer outra perspectiva - tal como a psicológica ou sociológica - é como interpretar uma poesia a partir da perspectiva dos interesses econômicos do poeta. Lembra Heschel: "Exegese adequada é um esforço de entender o filosofo em termos e categorias da filosofia, o poeta em termos e categorias da poesia, e o profeta em termos e categorias da profecia. Profecia é um modo de pensar tanto quanto de viver" (HESCHEL, 2011, p. xxvi).

\section{O PATHOS DIVINO COMO OBJETO DA EXPERIÊNCIA PROFÉTICA}

Deus em sua essência não é o objeto da experiência profética, o objeto da experiência profética é o pathos divino. Com isso, Heschel aponta para a especificidade do objeto fenomenológico do profetismo literário bíblico. Não o Ser divino em sua essência, atributos e propriedades, como o é para a teologia clássica. O objeto da experiência profética é o pathos divino. 
Os profetas não tinham teorias ou ideias sobre Deus. O que eles tinham era um understanding. Seu entendimento de Deus não era resultado de suas inquirições teóricas sobre o ser divino. Para os profetas, Deus era impressionantemente real e assustadoramente presente. Ou seja, o conjunto de imagens de Deus que o profetismo bíblico testemunha não diz respeito a qualquer espécie de exposição da natureza de Deus. Tais imagens expõem, sim, a preocupação divina a respeito do homem. Assim registra Heschel: "Eles descobriam atitudes de Deus mais do que ideias sobre Ele" (HESCHEL, 2011, p. 287).

Assim, no profetismo literário bíblico noções como bondade, justiça, sabedoria e unidade divinas aparecem em número muito menor que as declarações sobre o pathos divino, fato que, segundo Heschel, não tem recebido a devida atenção da teologia bíblica.

Mas, afinal, o que vem a ser a noção hescheliana de pathos divino? Por uma via negativa responderíamos, com Heschel, que "pathos não é uma substância, nem um atributo, nem uma qualidade imutável, nem um conteúdo absoluto do ser divino" (HESCHEL, 2011, p. 298). Ou, de uma maneira positiva: "Deus nunca é neutro, nunca está além do bem e do mal. Ele é sempre parcial na justiça" (HESCHEL, 2011, p. 298).

No dizer de Pearlman, "pathos é o objeto da experiência profética, que é incorporado para dentro de tal experiência com um fato fenomenológico." (PERlman, 1989, p. 91). Ou seja , o profeta não meramente sente tal realidade, ou a constrói misticamente. O profeta é desafiado por ela. Por isso, em contraste com o conhecimento especulativo, a atitude profética intuitivo-pensativa, na qual Deus é apreendido através de suas sensíveis manifestações, pode ser melhor caracterizada pelo termo undesrstanding, em inglês, ou verstannis, em alemão. (HESCHEL, 2011, p. 287)

Tal conhecimento, segundo Paolo Gamberini (1975), pode ser definido, em sentido lato, como compreensão ou inteligência, no sentido de intus-legere. Gamberini lembra que em hebraico há dois termos para dizer compreensão e inteligência: daath e binà. $\mathrm{O}$ primeiro tem um sentido mais de participação emotiva, o segundo de inteligência na consciência.

Bina deriva de bin, que significa além de 'intelligere', discernir, penetrar, saber sapiencialmente. O termo correspondente que Heschel usa em alemão é einsicht, em inglês insight, para contrapor ao conhecimento conceitual (speculative knowledge). O insight vê o que ao pensamento conceitual é 
impossível ver. A intuição vê o fenômeno internamente, acompanhado de um senso de surpresa (GAMBERINI, 2009, p. 35).

O outro termo, daath, indica uma participação de amizade, de amor, um envolvimento emocional com o outro. Deriva daí o verbo yada. Daatah Elohim, é a expressão clássica da experiência profética. Conhecer Deus é lançar-se na posse dele, amá-lo. Tal verbo não pode ser entendido como simples emocionalismo. Embora a dimensão emocional esteja presente, nela está implicada a noção de consciência intelectual com toda a gama de operações mentais que vêm a reboque, tais como apreensão, juízo, relação (GAMBERINI, 2009, p. 36)

Para Heschel, a profecia é "uma comunicação inspirada das atitudes divinas para a consciência profética. O pathos divino é o grau zero de todas essas atitudes" (HESCHEL, 2011, p. 288). Tal categoria teológica central do entendimento profético de Deus ecoa em quase todas as afirmações proféticas, constituindo-se no elemento teológico de tal experiência.

\section{O ACENTO TEOLÓGICO, NÃO PSICOLÓGICO}

O sentido essencial de pathos, entretanto, não tem uma conotação psicológica, como um estado da alma, mas uma conotação teológica, significando o envolvimento de Deus na história. Ele está engajado como Israel e tem participação no seu destino. A profundidade deste insight pode ser percebida somente à luz do despertar profético do mistério e transcendência de Deus. Para o entendimento bíblico de história, a ideia de pathos é tão central como a ideia de um homem feito à imagem de Deus o é para o entendimento da criação (HESCHEL, 2011, p. 298).

Por isso mesmo, tal envolvimento de Deus na história e da história em Deus, torna impossível à consciência profética a noção de Deus como o totalmente outro. Um Deus silencioso e envolto nas densas nuvens do desconhecido pode ser uma antítese interessante para um homem iludido com a sua própria claridade, mas a profecia é alheia a tal temática. Deus é aquele que está indo ao encontro do homem, sempre.

Também a noção do numinoso jamais foi uma categoria suprema para os profetas. Sendo o pathos divino o elemento central da sua consciência religiosa, não haveria lugar para o numem. Longe de ser uma noção intrinsicamente irracional, pathos é o estado no qual o profeta é capaz de perceber tanto 
moralmente quanto emocionalmente a afetação que sofre com a presença do divino (GAMBELINI, 2009, p. 73).

A esse respeito, Heschel lembra que o que Abraão encontrou não foi um numem, mas a plenitude do cuidado de Deus. A lei moral pode estar obscurecida, mas jamais estará suspensa na experiência profética de Deus. O verdadeiro ato endereçado a Abraão foi experimentado como cuidado e não como terror ante o numinoso.

Tal noção patética da experiência profética de Deus recoloca a questão da linguagem antropomórfica com toda a dinamicidade e tragicidade que lhe é própria, como expressão do pathos divino. Para Heschel, tal dinamicidade origina-se no pathos de Deus, e é devida sobretudo à polaridade entre amor (hesed) e ira de Deus, polaridade que não permite qualquer irreversibilidade de uma decisão divina sobre o homem (GAMBERINI, 2009, p. 73).

Dessa forma, segundo Gambelini (2009, p. 75) a noção de pathos permite pensar a transcendência divina sem prescindir do envolvimento de Deus na vida do seu povo. Se o pathos não diz respeito à essência de Deus, mas a uma relação entre Ele o homem, então, trata-se de uma realidade funcional mais que substancial, um ato divino mais que um atributo.

Daí a força da linguagem antromórfica do profetismo bíblico. Tal linguagem, num primeiro momento, pode ser confundida com uma espécie de confusão do pathos divino com um estado de ânimo, um puro sentimento, ou qualquer coisa de irracional e arbitrária. O sentido mais profundo de tal linguagem é ser a expressão de um ato realizado intencionalmente, dependente da vontade livre e resultado de uma decisão. O pathos divino é como uma ponte lançada sobre o abismo que separa o homem de Deus (GAMBERINI, 2009, p. 75).

Pelo viés da antromorfia dos escritos proféticos, o conceito de ira de Deus alcança a outra dimensão. A ira de Deus diz respeito a sua solicitude. Seu sentido mais profundo é que Deus não é indiferente ao mal que o homem experimenta na história. Mais que isso, ela também, a ira, jamais é algo definitivo. O homem pode mudar a decisão de Deus a seu respeito. Tal hermenêutica recupera, segundo Gambelini, a ira de Deus da contraposição marcionita, sempre latente na teologia cristã, na contraposição entre Novo e Antigo Testamento (GAMBERINI, 2009, p. 75).

\section{CONCLUSÃO}


A noção de pathos divino é o mais importante legado deixado pela filosofia da religião ou teologia profunda de Abraham Heschel. A transitividade do amor divino, sua concernência com os feitos e desfeitos da condição humana são o eco mais forte do profetismo bíblico. Que Deus está à procura do ser humano, mais do que este a procura daquele, é derivação mais potente deste eco.

Heschel radicalizou tal perspectivismo bíblico, pela via da abordagem fenomenológica da consciência profética, e com isso recolocou a categoria da paixão para além dos moldes da abstração e conceitualismo filosóficos. $\mathrm{O}$ amor de Deus não é um conceito, é uma força, uma presença, um atravessamento, uma experiência, um esmagamento que faz a vida alargar. $\mathrm{O}$ profeta esmagado por tal experiência é um homem unido, jamais fundido a Deus. Assim fazendo, o teólogo judeu tocou no calcanhar de Aquiles da teologia medieval judaica e também cristã: o axioma da impassibilidade. Em nome do conceito Deus, no alto de sua imutabilidade e imperturbabilidade, esvaem-se todas as dialéticas do devir, todas as aporias que derivam do pensar o infinito na contingência das finitudes.

Heschel desenterrou a mensagem do profetismo bíblico da camisa de força do conceito, das leituras cientificizantes cujas alcunhas psicológicas e sociológicas são como carimbos autoritativos a dar dignidade e sustentação para que o Sagrado faça entrada no mundo da técnica. Ao questionar o axioma da divina impassibilidade tocou nas polaridades imanência transcendência, finito infinito, Deus homem. Ofereceu a Deus faces tão humanas ao mesmo tempo que aos seres humanos, braços tão divinos, capazes de mudar o curso da historia. Tais dialéticas estavam enterradas sob a ideia de um Deus longe do devir das coisas do mundo humano. Sua abordagem da consciência profética descortinou ao mundo contemporâneo a linguagem do profetismo bíblico e a consequente potência de um pensamento filosófico teológico, capaz de livrar o ser humano atual das malhas da indiferença, da resignação, de um mundo controlado por maquinas. Um mundo avesso à consciência do mistério, à procura de milagres da vida e inerme à vida como um milagre.

\section{REFERÊNCIAS}

ALMEIDA, Edson Fernando. Do viver apático ao viver simpático. Sofrimento e morte. São Paulo: Loyola, 2006.

BALTHASAR, Urs von. Lo Spirito della Verità.Milano: Joca Book, 1972. 
BERKOVITS. Eliezer. Dr. A. J. Heschel's Theology of pathos.Tradition, vol. 6, n. 2, Spr-Sum, p. 67-104, 1964.

FRIEDMAN, Maurice S. Abraham Joshua Heschel. Philosopher of Wonder. Eugene,Oregon: Cascade Books, 2012.

GAMBERINI, Paolo. Pathos e Logos in Abraham J. Heschel.Roma: CittàNuova, 2009.

HESCHEL, Abraham J. Deus em busca do homem. São Paulo: Paulinas, 1975.

O homem a procura de Deus.São Paulo: Paulinas, 1974.

. O homem não está só.São Paulo: Paulinas, 1974.

. The Prophets. New York: Perennial Classics, 2011

JAEGER, John David.Abraham Heschel and the theolgogy of JurgenMoltmann.

Perpectives in Religious Studies, 24, Sum, p. 167-179, 1997.

KAPLAN, Edward; DRESNER, Samuel H. Abraham Joshua Heschel: profhetic witness. New Haven and London: Yale University Press, 1998.

LEONE, Alexandre. A imagem divina e o pó da terra. humanismo sagrado e crítica da modernidade em A. J. Heschel. São Paulo: Fapesp, 2002.

그. Mística e Razão.dialética no pensamento judaico. São Paulo: Perspectiva, $\overline{2008 .}$. Mística e Razão em Heschel. Arquivo Maaravi. Belo Horizonte, v. 1, n.2,

A oração como Experiência Mística em Abraham J. Heschel. REVER, São Paulo n.4, p. 42-53, 2003.

LUCHETTI BINGEMER, Maria Clara; REY PUENTE, Fernando (Orgs). Simone Weil e a filosofia. Rio de Janeiro: PUC/Loyola, 2011.

PEARLMAN, Lawrence. Abraham Heschel's idea of revelation, Atlanta:Scholars Press, 1989.

SCHWANTES, Milton. Amós. Estudos e meditações. Petrópolis/São Leopoldo: Vozes/Sinodal, 1987.

VILELA-PETIT, Maria da Penha. A crise das ciências segundo Simone Weil e Edmund Husserl. In: LUCHETTI BINGEMER, M. C; REY PUENTE, Fernando (Orgs). Simone Weil e a filosofia. Rio de Janeiro: PUC/Loyola, 2011. 